\title{
A política industrial chinesa como determinante de sua estratégia going global
}

\author{
GILMAR MASIERO \\ DIEGO BONALDO COELHO*
}

The Chinese industrial policy as determinant of its "going global" strategy.

China has experienced not only high rates of economic growth as well as an unprecedented competitive international insertion since the turn of the century. This process was not guided solely by market forces or influenced by Government intervention in the economy. Although much has been argued that China's "going global" strategy is rooted in state action, and especially its policy of exchange rate depreciation and trade policy incentives for exports and investments abroad, we argue that the major determinant of this strategy, which established the basic conditions for industrial competitiveness, was its industrial policy. The focus of this article is on the changes in China's industrial structure, emphasizing that Chinese industrial policy is a central determinant of its international insertion strategy.

Keywords: China; development strategy; industrial policy; strategy "going global". JEL Classification: O21; O25.

\section{INTRODUÇÃO}

O início do século XXI está sendo marcado por grandes modificações na geografia econômica internacional, motivadas, em grande parte, pelo ressurgimento da China, cuja trajetória econômica recente propiciou resultados que permitem considerá-la uma das grandes potências político-econômicas da atualidade. Com taxas de crescimento econômico e de exportações e importações elevadas, bem como de receptividade e realização de investimentos, a China, de uma economia pouco expressiva nos anos 1990, já havia se tornado, no fim da primeira década

\footnotetext{
* Professor da FEA-USP. E-mail: gilmarmasiero@gmail.com; Doutorando do PPGA/FEA-USP e Professor do Departamento de Economia da FEA/PUC-SP. E-mail: dcoelho@usp.br. Submetido: 27/janeiro/2012; Aprovado: $13 / \mathrm{março/2013.}$
} 
dos anos 2000, o segundo PIB do mundo, a principal origem internacional de produtos (exportações) e o segundo destino mundial de Investimento Direto Estrangeiro - IDE (UNCTAD, 2010; WTO, 2011).

Para muitos analistas, esses expressivos resultados atingidos pelos chineses são frutos de uma nova trajetória de crescimento, direcionada, sobretudo, por uma estratégia going global, caracterizada por forte e agressiva inserção de suas empresas e negócios em terceiros mercados, seja via exportações e/ou investimento direto no exterior. Com isso, a agenda internacional de pesquisa tem se mobilizado e se dedicado ao estudo das determinantes dessa vigorosa estratégia, tanto das suas diretrizes quanto dos seus mecanismos de realização. Em seus resultados mais disseminados, muito se tem argumentado sobre a centralidade do Estado e de sua atuação. Argumenta-se que a internacionalização da China (Zweig, 2002) e a sua transformação (Nolan, 2004), que a posicionaram entre as primeiras economias do mundo, bem como permitiram ao país ser reconhecido por muitos como o workshop of the world (Gao, 2011), advêm principalmente do seu Estado, destacadamente de sua intervenção na economia.

Contudo, é importante ressaltar que a mera citação - ou evocação - do Estado como ator responsável pelo desempenho econômico e expansão internacional chineses ainda deixa muitas questões em aberto, dado que não qualifica o tipo, a maneira, o padrão e a intensidade dessa participação, tampouco as suas determinantes e estratégias pretendidas. Ao se analisar o processo de desenvolvimento econômico da maior parte dos países emergentes, ou mesmo dos desenvolvidos, se observa que o Estado, em maior ou menor grau, também sempre esteve - e está presente na determinação de suas estratégias de desenvolvimento.

Nesse sentido, a questão não reside meramente na participação do Estado por si só, mas em como ela é realizada e de sua articulação com outros atores e agentes. Pois, sendo o desenvolvimento econômico de um país um processo histórico, que passa pela acumulação de capital e aumento da produtividade da economia, levando ao crescimento sustentando da renda por habitante e da melhoria dos padrões de vida de sua população, sua realização passa pela formulação de uma estratégia nacional. Esta, segundo Bresser-Pereira (2006), pode ser entendida como uma ação concertada de uma nação, que, por meio de pautas e diretrizes para empresários, trabalhadores, classes médias profissionais e a própria burocracia do Estado, tem como critério fundamental defender o trabalho, o conhecimento e o capital nacional, seja protegendo-os da competição internacional, seja definindo políticas para torná-los capazes de competir.

Todavia, a despeito de ser o objetivo de qualquer país, a formulação e consecução de uma estratégia de desenvolvimento não é simples, dada ou certa. Inúmeros estudos e pesquisas são elaborados com objetivo de se "estimar" - por que não determinar? - as diretrizes e padrões estratégicos possíveis para a realização sustentável do desenvolvimento. Porém, verifica-se que independente dos estilos e/ou existência de políticas intervencionistas governamentais, tais estratégias são resultantes das pressões e articulações dos atores em âmbito nacional e de complexos 
contextos político-econômicos internos e externos, não se encontrando métrica absoluta, sobretudo prescrição; são processos fortemente contextualizados.

Com relação à China, o início de seu desenvolvimento e inserção internacional recente parece ser resultante de amplo processo de retomada de uma estratégia nacional de desenvolvimento no país, cujo marco histórico é dado nas reformas de 1978 a 1993, as quais, segundo Naugthon (1996), foram realizadas "fora do plano", de forma gradual e experimental, de acordo com as pressões econômicas do momento. Inclusive, as direções e ações estratégicas tomadas pela China a partir dessas reformas e ao longo dos anos 1990 levaram Perkins (2001) a indagar se os chineses, em busca de seu desenvolvimento, estariam gerenciando um novo modelo ou realizando uma reprise da experiência do Leste Asiático.

A partir da indagação de Perkins (2001), o presente artigo, visando identificar a principal determinante da estratégia going global, considera o papel do Estado no desenvolvimento recente da economia chinesa, concentrando-se em analisar as suas diretrizes e meios de intervenção adotados. Busca descrever as transformações que essa estratégia e as políticas que a fundamentam causaram na estrutura industrial chinesa, principalmente de seus setores metal-mecânico, eletroeletrônico e químico, que, no entendimento a ser defendido, possibilitaram ao país registrar vigoroso desenvolvimento e inserção internacional competitiva vis-à-vis outros países. Tais objetivos se justificam principalmente pelo fato de que as principais explicações da inserção internacional chinesa concentram-se apenas na análise da condução de suas políticas cambiais (depreciação da moeda) e/ou comerciais (financiamentos e incentivos para exportações e importações), o que, do ponto de vista deste artigo, tem se demonstrado uma interpretação limitada, ainda que fundamental e tampouco menor ou excludente.

\section{A INDUSTRIALIZAÇÃO E O PAPEL DO ESTADO}

Estratégias nacionais de desenvolvimento normalmente não são consensuais, sendo possível contestá-las a partir de diferentes perspectivas. Tais características derivam principalmente das inúmeras experiências de desenvolvimento econômico observadas, algumas mais aceleradas outras menos, sendo difícil se definir o melhor caminho a ser seguido. Contudo, mesmo diante de infinitas possibilidades, algumas componentes se apresentam como fundamentais e imprescindíveis a qualquer estratégia de desenvolvimento, dado que se constituem importantes determinantes dos grandes saltos de produtividade e crescimento da economia, dentre os quais papel primordial é dado à industrialização (Acemoglu, 2009). Não há análise do desenvolvimento contemporâneo que não resguarde papel privilegiado à industrialização (Kaldor, 1970; Chenery, Robinson \& Syrquin, 1986).

Conforme analisou Krüger (2008), a trajetória de crescimento econômico ocorre por meio da realocação de recursos entre os setores primário, secundário e terciário, que, determinada pela produtividade, é caracterizada pela queda do setor agrícola e aumento dos industriais, num primeiro momento, e, posteriormente, do 
aumento do setor de serviços. Segundo Amsden (2009), esse padrão centraliza a importância das mudanças estruturais dos países, dado que o crescimento econômico ocorre pela realocação dos fatores de produção de setores e atividades de baixa produtividade para os de alta, sendo nesse processo o setor industrial fundamental, pois é ele o de maior potencial de incrementos da produtividade, dados seus fatores tecnológicos, encadeamentos intra e intersetoriais e externalidades pecuniárias.

Não obstante a centralidade do processo de industrialização, Fajnzylber (1983) destacou que alguns setores são mais dinâmicos do que outros e a inserção internacional é fator preponderante. Contribuições importantes nesse sentido foram dadas pelos autores da Comissão Econômica para a América Latina - Cepal, os quais observaram que, a despeito da industrialização ser realizada primeira e mais facilmente por meio de uma indústria de bens de consumo, o crescimento econômico das economias capitalistas industrializadas é fortemente impulsionado pelos bens de produção e intermediários, dados estes serem setores agregadores de valor e responsáveis por desencadear as demais indústrias. Para eles, economias que não conseguem desenvolver satisfatoriamente sua indústria de bens de produção e intermediários terão consideráveis entraves estruturais para maior dinamização de seu crescimento econômico.

Os dados de comércio internacional indiretamente corroboram essa linha de análise, ao evidenciar que os padrões comerciais dos países considerados global players e que executaram suas inserções internacionais possuem suas pautas de exportação fortemente concentradas em produtos manufaturados de setores-chave do encadeamento industrial. De acordo com a World Trade Organization (2010), mais de $70 \%$ das exportações da América do Norte e da Europa, em 2009, foram de produtos manufaturados, principalmente das indústrias de bens intermediários e de capital, com destaque para os setores químico, metal-mecânico e eletroeletrônico, enquanto que para a América do Sul apenas 27,4\% das exportações pertenceram a esses setores. Já a Ásia registrou aproximadamente $80 \%$ das suas exportações em produtos manufaturados para o mesmo ano, com forte participação do setor eletroeletrônico, seguido de metal-mecânico e químico.

Nesses termos, diferentes concepções teóricas e argumentos mais ideologizados e historicamente caracterizados pelo dissenso têm norteado o debate sobre o papel do Estado nas estratégias nacionais de desenvolvimento, e, principalmente, na industrialização dos países, concentrando-se, atualmente, na pertinência ou não de políticas industriais no contexto da economia global (Rodrik, 2004 e 2008). Ao passo que hiperglobalistas, como Ohmae (1990), defendem que os Estados e as questões nacionais não são mais relevantes, dado que a "combinação de tecnologias revolucionárias de transportes e comunicações e o poder crescente das empresas transnacionais retirou o poder econômico do controle do estado-nação" (Dicken, 2010, p. 196), outros autores, dentre eles, Castells (1999), Dicken (2010), Porter (1989), Gilpin (2001), Vietor (2007) e Stopford (1999), defendem perspectiva contrária, argumentando que "exatamente por causa da interdependência e abertura da economia internacional que os Estados devem empenhar-se em promover o 
desenvolvimento de estratégias em nome de seu empresariado" (Castells, 1999, p. 108), sendo considerados importantes atores na economia global.

Conforme analisou Lall (2000), esse debate sobre as estratégias de desenvolvimento, e particularmente o papel dos Estados em seu processo, destacadamente na industrialização como a sua força motriz, obtiveram contornos e verve fortemente liberais como mainstream no contexto da virada do século XX para o XXI, tornando o clima para política industrial hostil e as políticas industriais seletivas economicamente indesejáveis e prejudiciais. Buira (2004) foi mais enfático nessa percepção, afirmando que o Consenso de Washington negou aos governos qualquer papel na promoção do crescimento de novos setores industriais, sendo descartada qualquer forma de política industrial. Não por acaso, como frisou Rodriguez (2007), ao longo dos anos 1990 mais de 49 países iniciaram seus processos de abertura econômica a partir das prescrições do Consenso de Washington, dando proeminência às forças de mercado em detrimento das intervenções governamentais para promoção do desenvolvimento.

Pack e Saggi, (2006), Noland e Pack (2005) e Bailey, Lenihan e Singh (2007) foram além, destacando que, a despeito da implementação do receituário de Washington por muitos países, os resultados atingidos por essas reformas não foram satisfatórios, desapontando muitas das nações que adotaram medidas liberalizantes - por vezes radicais - para melhorarem seu dinamismo industrial e crescimento econômico. Dessa maneira, certa reconsideração do papel dos Estados, via políticas mais dirigistas e intervencionistas, voltaram ao centro das atenções, principalmente após a crise econômica de 2008, alinhando-se, ainda que com restrições quanto às suas formas de realização, com os autores que entendem os governos como responsáveis por induzir a competitividade (Porter, 1989; Castells, 1999; Vietor, 2007; Dicken, 2010). A atenção foi dada, sobretudo, na relevância das políticas industriais no contexto da economia global, motivada, em grande parte, pelos resultados alcançados pelos países do Leste Asiático no período recente, como destacado por Wade (2010).

Para Pack e Saggi (2006), o tema das políticas industriais ficou novamente perceptível pela forte - e compreensível - busca pelos países da América Latina e da África por novas fórmulas de crescimento econômico, levando muitos policy-makers a manifestarem publicamente seu apreço por tais políticas, diante, principalmente, do desempenho dos asiáticos, destacadamente a China. Atualmente, vários acadêmicos alinham-se com essa retomada, entre eles Wade (2010), Aiginger (2007), Soete (2007), Rodrik (2004 e 2008) e Lall (2004), direcionando seus focos de pesquisa para as políticas industriais e, fundamentalmente, para o questionamento de sua relevância na promoção do crescimento dos países. Nesse sentido, a China tem se colocado como caso imprescindível de análise, uma vez que, como será demonstrado, optou por políticas industriais como importante pilar na realização de sua estratégia de desenvolvimento, o que, no âmbito de uma economia global, demonstrava-se na contramão dos demais países alinhados com o mainstream e as prescrições do Consenso de Washington. 


\section{O PROCESSO DE INDUSTRIALIZAÇÃO E INSERÇÃO INTERNACIONAL DA CHINA: UMA QUESTÃO DE POLÍTICA INDUSTRIAL}

Os resultados econômicos atingidos pela China alinham-se com a perspectiva teórica apresentada e indicam o papel fundamental de sua indústria, em especial o caráter e a dinâmica de seu processo de industrialização, na inserção internacional recente do país. Os indicadores econômicos referentes ao seu PIB rapidamente permitem constatar a importância e lugar privilegiados ocupados pela indústria na participação e promoção do crescimento chinês: sua composição por setor de atividade econômica, durante o período 1990-2009, revela que a agricultura historicamente reduz a sua participação, ao passo que os serviços aumentam seu peso e a indústria se mantém alta e preponderante. Entre 1990 e 2009, a China atingiu uma média de $46 \%$ de participação da indústria em seu PIB, enquanto a média mundial para o mesmo período foi de $29 \%$ (World Bank, 2011).

A China também apresenta, em termos de valor agregado industrial, crescimentos sucessivos e expressivos acima da média mundial. De 1990 a 2009 os chineses registraram incremento médio de $12 \%$ ao ano, e o mundo, por sua vez, apenas $2 \%$ (World Bank, 2011). $\mathrm{Na}$ indústria manufatureira, compreendidos os grupos de 15 a 37 da ISIC - International Standard Industrial Classification, que inclui setores como o químico, metal-mecânico e eletroeletrônico, constata-se expressiva contribuição para o crescimento do valor agregado industrial. Nas duas últimas décadas do século $\mathrm{XX}$, a indústria manufatureira chinesa aumentou em média 9,5\% ao ano sua participação no PIB do país. Essa participação, entre 1991 e 2000 , atingiu $13 \%$ ao ano em média, mantendo praticamente o mesmo ritmo de expansão (12\% ao ano) no período posterior, de 2001 a 2007 (World Bank, 2011). Nos últimos trinta anos, este significativo ritmo de crescimento registrado permitiu que seus setores manufatureiros alcançassem a participação média de 33\% no PIB - resultado visivelmente superior dentre os principais países em desenvolvimento e regiões do mundo, com média de apenas 18\% (World Bank, 2011).

Ao que tudo indica, esses resultados não foram atingidos aleatoriamente, mas pela existência de um planejamento industrial específico, formulado, orientado e liderado pelo Estado no âmbito de uma estratégia nacional de desenvolvimento do país. Esta afirmação encontra seu respaldo histórico-institucional a partir das reformas de 1978 - momento em que a indústria chinesa iniciou sua reorganização e estratégia de desenvolvimento, tendo seu momento mais evidente e contundente em 1989, quando o Estado chinês assumiu institucionalmente a importância da indústria no crescimento do país e deliberadamente optou pela realização de políticas específicas, com seu Conselho de Estado emitindo as diretrizes para uma política industrial em seus Oitavo e Nono Planos Quinquenais.

Nesse processo, segundo Nolan (2001), um grupo de 120 grandes empresas de setores de importância estratégica foi selecionado pelo Conselho de Estado para liderar a expansão industrial chinesa. Entre elas encontrava-se 8 empresas de geração de eletricidade, 3 mineradoras de carvão, 6 empresas automobilísticas, 10 eletrônicas, 8 siderúrgicas, 14 de produção de máquinas, 7 químicas, 5 construtoras, 
5 transportadoras, 6 aeroespaciais e 5 farmacêuticas - ou seja, empresas de setores tradicionalmente caracterizados por fortes ganhos de escala e escopo, que, na visão de Chandler (1994), são os mais importantes para a modernização e progresso industrial e tecnológico das sociedades avançadas.

As diretrizes selecionadas pelo Conselho de Estado chinês para a formulação de uma política industrial foram dadas, em grande parte, pelos sérios problemas que a estrutura industrial do país detinha à época. A indústria chinesa do final dos anos 1980 apresentava sérios entraves ao seu desenvolvimento, tais como: i) excesso de capacidade de produção fortemente desproporcional ao baixo desenvolvimento dos setores agrícola, energético, de transporte e extrativo mineral; ii) desproporção entre o elevado desenvolvimento da indústria de nível médio vis-à-vis ao baixo da indústria avançada; iii) distribuição regional irracional das indústrias e subutilização das vantagens comparativas regionais; iv) baixo empenho e capacidade de coordenação e organização entre as empresas; v) concentração industrial excessivamente baixa, tornando a indústria extremamente ineficiente.

A partir desse diagnóstico, o governo chinês optou por formular uma política industrial seletiva e orientada para meios capazes de culminar na consolidação de setores industriais considerados estratégicos - como os de alta tecnologia e de capital-intensivos. O desenvolvimento desses setores e a sua aquisição de competitividade seriam planejados a partir da intervenção do Estado sobre os negócios e teriam sua condução combinada com outros planejamentos no âmbito de sua estratégia nacional de desenvolvimento, como as políticas de comércio exterior, de atração de investimento estrangeiro, cambial e tecnológica. E, não obstante as empresas e os setores selecionados para serem estimulados, outros deveriam ter a sua produção suprimida ou desestimulada, entre eles os de bens e máquinas de baixa qualidade, bens de consumo duráveis de alto consumo elétrico, bens de luxo, bem como a eliminação da exportação de bens escassos no mercado interno.

Institucionalmente, as bases dessa política industrial foram estabelecidas no Plano Decenal (1991-2000), sendo especificamente detalhadas nas Diretrizes de Política Industrial para os anos 1990. Já as ações de consecução de tais diretrizes ocorreram por meio de quatro Planos Quinquenais. Sendo, a partir dessas bases institucionais, que a realização da estratégia industrial chinesa assumiu contornos bem definidos, delineados por meio de ciclos, com os dois primeiros de fundamentação, realizados durante o Oitavo (1991-1995) e o Nono (1996-2001) Planos, e, posteriormente, mais dois ciclos, de consolidação de especificidades, dados pelos Planos subsequentes, o Décimo (2001-2005) e Décimo Primeiro (2006-2010).

A análise das prioridades dos dois primeiros ciclos revelam a escolha estratégica do Estado por primeiramente consolidar as bases da industrialização do país, direcionadas para estimular setores dinamizadores e criar condições estruturais e microeconômicas para o desenvolvimento competitivo dessas indústrias. No primeiro ciclo, as ações possuíram sua consecução dada com forte participação do Estado, que passa a ser decisivo na alocação dos recursos, sendo responsável pelo provimento de infraestrutura, fornecimento de energia e matérias-primas, além de subsidiar sua base tecnológica via importação de bens de produção de alta tecnologia, prin- 
cipalmente no setor metal-mecânico, com vistas a incrementar a manufatura para bens exportáveis com maior valor agregado. Já o segundo ciclo foi marcado pela determinação de metas de longo prazo, com fortes intervenções governamentais de curto prazo, no qual se buscou otimizar a estrutura industrial dos setores considerados prioritários no primeiro ciclo e em processo de consolidação no posterior por meio da promoção de economias de escala e da reorganização produtiva, que seriam dadas com a formação de grandes empresas e grupos empresariais.

A política industrial chinesa pretendeu, em seus dois primeiros ciclos (1991-1995; 1996-2001), criar as condições basilares por meio de incentivos e subsídios que possibilitassem consolidar e expandir os setores prioritários em duas frentes estratégicas: incrementá-los tecnologicamente por meio da importação de bens de capital e recepção de investimento direto (IDE) e direcioná-los à inserção comercial internacional por meio da exportação. Os resultados registrados revelam considerável eficácia, uma vez que, em 1991, 22\% das exportações do país eram de produtos primários, enquanto em 2001 essa participação caiu para 9\%. Em contrapartida, as exportações de manufaturados, que compuseram $77 \%$ da pauta exportadora em 1991, atingiram 90\% em 2001 - no setor estratégico de máquinas e equipamentos essa participação saltou de 9\%, em 1991, para 35\%, em 2001 (CSY, 2009). O Gráfico 1 ilustra essas transformações na estrutura industrial chinesa ao longo dos quatro Planos Quinquenais que caracterizam os ciclos considerados neste trabalho.

Gráfico 1: Composição da pauta de exportações chinesas, por categorias de produtos primários e de manufaturados, entre 1991 e 2008, em porcentagem

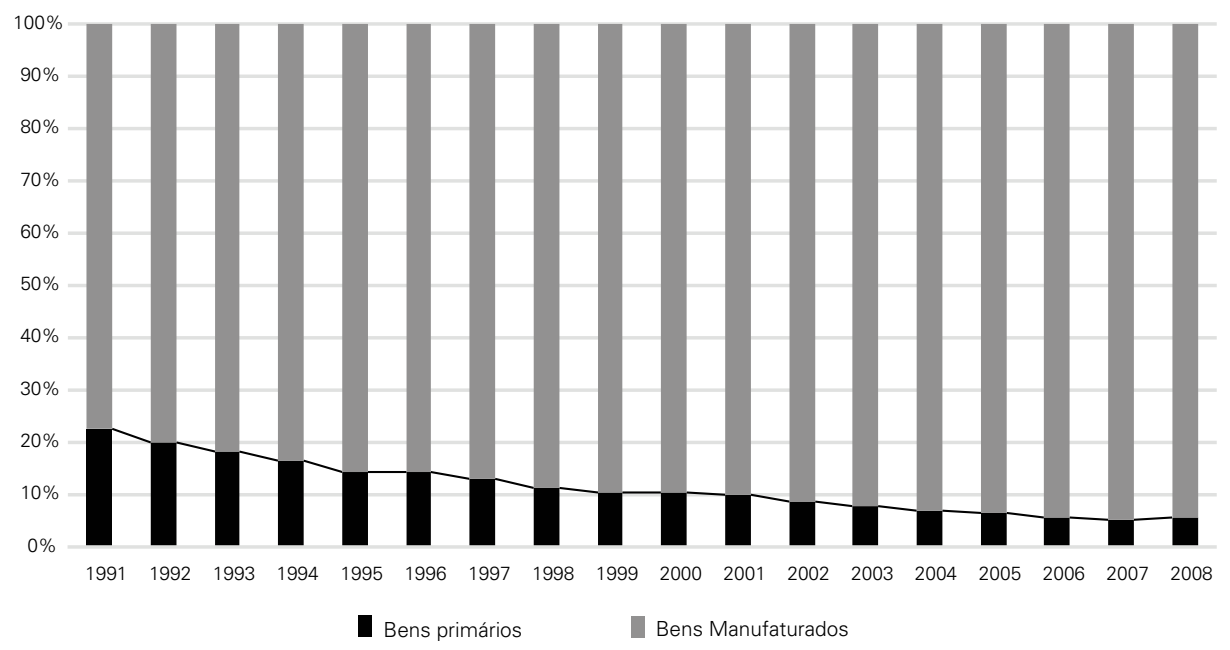

Fonte: Elaborado pelos autores a partir do Chinese Statistical Yearbook.

Neste período, conforme Lin (2001), além de uma maior liberalização receptiva de investimento estrangeiro para áreas de interesse do Estado, vários programas de desenvolvimento tecnológico, estabelecidos nos anos 1980, começaram a 
dar resultados. Dentre os principais, encontravam-se: o Programa de Tecnologias-Chave, de 1982, em que o governo disponibilizava tecnologias-chave para algumas empresas desenvolvê-las e comercializá-las; o Programa 863, de 1986, que criou vários laboratórios de tecnologia avançada; o Programa Torch, de 1987, de ênfase na educação em ciência e tecnologia; o Programa Nacional de Novos Produtos, de 1988, responsável por ajudar as empresas a adquirir ou desenvolver novos produtos; e, por fim, o Programa Nacional de Centros de Pesquisa em Engenharia e Tecnologia, que criou vários centros de pesquisa importantes, desde 1992.

Posteriormente, a China promoveu nova fase de sua política industrial por meio de mais dois ciclos, do Décimo (2001-2005) e Décimo Primeiro Planos (2006-2010), com vistas a acelerar o desenvolvimento da competitividade de seus setores eleitos como prioritários. $\mathrm{Na}$ busca deste objetivo, o Estado chinês, a partir de seu Décimo Plano, promoveu as seguintes ações: i) ajustes na estrutura de produção, estimulando a ampliação e uso de novas tecnologias e fornecendo suporte a grandes corporações de maneira a acelerar suas reestruturações; ii) reorganização interna dos setores, formando grupos empresariais de grande escala de produção, bem como fomentando a formação de empresas de médio e pequeno portes, as quais fabriquem produtos específicos; iii) estímulo à modernização dos sistemas de gestão permitindo a participação privada em empresas estatais; e, iv) reorientação internacional, ingressando na Organização Mundial do Comércio e incentivando a internacionalização de suas empresas (Marrone, 2006).

Nestes dois ciclos, três setores obtiveram considerável destaque: o metal-mecânico, o eletroeletrônico e o químico. Para estes setores industriais, em específico, o Conselho de Estado decidiu, pela primeira vez de maneira mais explícita, estipular metas de desempenho para garantir um rápido desenvolvimento de seus vários segmentos. Buscou incrementar a competitividade por meio da consolidação e intensificação de suas vantagens comparativas, tendo seus principais indicadores organizados em torno da produção, da reestruturação tecnológica e da reorganização industrial. De acordo Heiden (2011), grande parte desta reorganização contou - e ainda conta - com a atração e incentivo do capital internacional, que tem sido encorajado, restrito ou mesmo proibido, de acordo com as diretrizes do Foreign Investment Industrial Guidance Catalogue, publicado em 1995 e com sua última versão dada em 2011.

\section{A POLÍTICA INDUSTRIAL CHINESA PARA SEUS SETORES-CHAVE: METAL-MECÂNICO, QUÍMICO E ELETROELETRÔNICO}

Os indicadores industriais e comerciais chineses evidenciam que a realização de sua política industrial impactou substancialmente a configuração industrial do país, conforme suas bases institucionais e seus objetivos estratégicos estipulados no início dos anos 1990. Não se trata apenas do alcance de metas e objetivos, mas também do nível de seu estabelecimento e a sincronização do tempo estipulado 
para a sua realização, podendo ser considerado um processo sem precedentes contemporâneos.

No que concerne a sua organização industrial, verifica-se que, em 2000, ao fim dos dois primeiros ciclos de sua política industrial, por exemplo, a China possuía 162.885 empresas industriais, passando para 434.364 empresas no ano de 2009 crescimento de $167 \%$ (CSY, 2010). A composição do porte dessas empresas também teve sua distribuição alterada, conforme orientação estratégica e planejamento dos Planos Quinquenais dos anos 2000. Enquanto as empresas de grande porte representavam $5 \%$ do total de empresas industriais em 2000, essa participação se reduz para 0,75\% em 2009 (CSY, 2001 e 2010). Desta maneira, evidencia-se a busca do governo chinês por consolidar setores, formando, como estipulado a partir de seu Nono Plano Quinquenal, grupos capitaneados por megaempresas âncora, com ganhos de escala capazes de torná-las internacionalmente competitivas.

$\mathrm{O}$ crescimento do número de empresas e a sua redistribuição por porte foram acompanhados por modificações em propriedade. Dentre as empresas industriais domésticas chinesas, $32 \%$ eram estatais, do tipo state-owned enterprises (todos os ativos de propriedade do Estado), no ano 2000, contra apenas 3\% de participação em 2009. Se consideradas todas as empresas nas quais o Estado possui relação em maior ou menor grau, compreendidas aqui aquelas de sua propriedade, as estatais, e as que possuem algum tipo de sua participação (state-holding), o número cai de 53.489, em 2000, para 20.590, em 2009 - uma redução de 61,5\%. Há, assim, uma diminuição do número relativo de empresas industriais domésticas estatais ou com participação do estado no total de empresas industriais, de 33\%, em 2000, para $5 \%$, em 2009. Em contrapartida, o setor privado aumentou sua participação no total de empresas industriais domésticas, de 13,59\%, em 2000, para 59\%, em 2009 (CSY, 2001 e 2010).

Com relação à indústria metal-mecânica, metas específicas determinavam que o setor deveria apresentar taxas elevadas de crescimento, tanto em volume quanto em valor adicionado, além de exportações e produtividade crescentes. Para a sua reestruturação tecnológica, ficou estabelecido que essa indústria seria direcionada a produtos considerados prioritários, tais como: equipamentos técnicos para segurança nacional, aqueles relacionados ao setor automobilístico, os equipamentos para modernização do setor agrícola e as máquinas-ferramenta, buscando, dessa maneira, equilibrar a oferta e a demanda na indústria chinesa. A pretensão exposta neste caso era a de não apenas permitir que a indústria chinesa como um todo fosse atendida primordialmente pela sua indústria metal-mecânica doméstica, mas, também, estimular a qualidade de seus produtos, uma vez que metas de valor adicionado e conteúdo tecnológico foram estipuladas.

Para alcançar este objetivo, o governo chinês seguiu implementando centros tecnológicos para inovação em todas as empresas-chave do setor, as quais, de acordo com as pretensões da política industrial, deveriam ser capazes de desenvolver e comercializar seus próprios produtos de forma independente (Lin, 2001). Ainda com relação à promoção da competitividade, a política industrial atuou fortemente na articulação e cooperação entre as empresas consideradas mais fortes e capazes 
pelo Estado, mesmo que de setores, regiões e estruturas societárias diferentes. Desta maneira, o governo definiu a meta de formação de grupos corporativos de larga escala, os quais teriam direitos de propriedade independentes, seriam competitivos internacionalmente e constituiriam o alicerce da indústria de máquinas do país. Buscava-se uma intensa reorganização industrial, que fosse capaz de otimizar a produção por meio de ganhos de escala e pelo fortalecimento de elos da cadeia produtiva a partir de uma base industrial de fornecimento que também fosse muito bem articulada e competitiva.

Como previsto na política industrial implementada, o movimento de concentração em torno de grandes e médias empresas para se atingir ganhos de escala, por um lado, e a ampliação e fomento de empresas para produtos específicos, de outro lado, parecem ter alcançado as finalidades almejadas. Tal resultado se torna mais perceptível ao se analisar os principais rankings empresariais mundiais. Dentre os quinze maiores países produtores de máquinas-ferramenta - de corte e conformação do mundo, a China, em 2009, já se apresentava como a maior produtora mundial em valores monetários.

A indústria química também passou por modificações substanciais. Escolhida como prioritária pelo governo chinês, tendo em vista sua característica de importante fornecedora de matérias-primas básicas para diversos elos da cadeia industrial, capaz de alavancar e diversificar a indústria como um todo, teve três segmentos químicos inicialmente contemplados como objeto de incentivos e injeção de recursos pelo Estado: agroquímicos (pesticidas e fertilizantes), materiais químicos básicos (orgânicos e inorgânicos) e química fina (reagentes químicos e aditivos) (China Chemical Reporter, 1996; Marrone, 2006).

A ênfase nestes três segmentos não foi aleatória, dado que para a realização das diretrizes estratégicas adotadas em sua política industrial era fundamental à China o processamento de produtos químicos que suprissem tanto às necessidades e forte expansão de seus setores industriais, principalmente aqueles objeto de políticas, tais como o metal-mecânico e eletroeletrônico, quanto à agricultura e economia rural - estas últimas também consideradas pelo Conselho de Estado como fundamentais para o desenvolvimento do interior do país. Ademais, era importante investir em setores de maior valor agregado, como a química fina, capazes de dinamizar a indústria em termos tecnológicos e econômicos.

As metas estabelecidas para a indústria química chinesa estavam relacionadas ao desempenho, alinhadas e direcionadas à consolidação e dotação da capacidade de oferta e competitividade para suprir o mercado interno, num primeiro momento, e, posteriormente, para atender os mercados externos. Após os primeiros resultados alcançados, com ampla superação das metas, o governo chinês pretendeu ser mais agressivo, não restringindo suas ações apenas à produção e consolidação setorial, mas introduzindo, pela primeira vez, a qualidade (produto) e proteção ao meio ambiente e segurança no trabalho (processo) no escopo das ações de política industrial para o setor químico.

A indústria química do país atingiu, em 2009, o segundo lugar no mundo, com um faturamento líquido $6 \%$ inferior ao da indústria dos Estados Unidos, primeira 
do ranking - que poderá ser ultrapassado nos próximos anos, uma vez que o ritmo de crescimento chinês vem sendo puxado pela extraordinária evolução do Produto Industrial Bruto do setor, que no período de 2000 a 2009 foi de $472 \%$; período em que houve forte expansão do número de empresas da indústria química chinesa, saltando de 15.565, em 2000, para 37.544, em 2009 (CSY, 2001 e 2010).

Para seu setor eletroeletrônico, dentre os objetivos determinados pela política industrial chinesa ao longo de seus ciclos, listavam-se a redução da dependência dos bens importados, e, consequentemente, a constituição de capacidade produtiva doméstica. Para cumpri-los, as ações do Estado se concentraram primeiramente na redução da dependência produtiva externa, por meio da atração, via investimento externo, da produção estrangeira de produtos do setor que, relativamente mais intensivos em trabalho e com tecnologia consolidada, teriam como motivadores de migração para a China as vantagens locacionais, principalmente a abundância de mão de obra. Destaca-se também, como estratégia do governo chinês, o incremento da capacidade produtiva doméstica, com incentivos governamentais (fiscais e creditícios) amplamente concedidos na implementação de parques industriais e zonas francas (Boulton, 1997).

Essas ações permitiram à indústria eletroeletrônica chinesa expandir rapidamente seu faturamento, superando taxas acima de $12 \%$ ao ano nos primeiros anos da realização da política industrial. Todavia, apesar dos resultados expressivos nos indicadores estruturais, estratégicos e conjunturais, a indústria eletroeletrônica chinesa ainda se apresentava frágil em algumas dimensões, como Pesquisa e Desenvolvimento $(\mathrm{P} \& \mathrm{D})$, não se fortalecendo na mesma velocidade e intensidade. As fragilidades do setor com relação às suas dimensões-chave em termos estratégicos foram rapidamente tratadas pela política industrial do país em seus Planos Quinquenais. Na busca por promover o alinhamento entre o crescimento dos principais indicadores de mercados (como produção, vendas e faturamento) com a P\&D e projeto defasados, o governo chinês rompeu o padrão de inovação, passando a fornecer, seletivamente, apoios mais robustos aos segmentos do setor eletroeletrônico considerados prioritários, classificando os investimentos em projetos de três tipos: os competitivos, estruturais e de bem-estar público.

Deste modo, a política industrial chinesa começou a intervir na indústria eletroeletrônica, utilizando-se do Estado como seu principal provedor de projetos de natureza estrutural e competitiva, os quais foram articulados com diversos mecanismos e instrumentos de incentivos, de escopos gerais e específicos. Esses programas foram conduzidos por meio de um número considerável de instituições de apoio à indústria eletroeletrônica, dentre as quais se destacaram o Ministério da Indústria Eletrônica (MEI) e a Comissão Estatal de Ciência e Tecnologia (SSTC). Estas instituições, responsáveis pelas principais atividades e ações relacionadas à indústria eletroeletrônica, orientadas pelas diretrizes estratégicas determinadas no âmbito dos Planos Quinquenais, reportam-se diretamente ao Conselho de Estado. Elas coordenaram os esforços governamentais concentrados para que os incrementos desses setores fossem realizados por meio de inovações endógenas (indigenous innovation), aplicação de tecnologia, consolidação da indústria (clustering) e cooperação internacional. 
O impulso que a indústria eletroeletrônica chinesa adquiriu por meio e a partir de sua política industrial durante os anos 1990 e a primeira década dos 2000 pode ser verificado na análise de seus principais indicadores, organização e resultados, em que se nota que as estratégias e metas colocadas, principalmente aquelas relacionadas à competitividade e padrão tecnológico obtiveram êxito. Ao observar alguns dos produtos mais representativos do setor eletroeletrônico, tais como, no segmento elétrico, motores e geradores, e nos eletrônicos, linha branca, televisores e microcomputadores, constatam-se incrementos acentuados em produção, com grande impacto internacional.

\section{A ESTRATÉGIA GOING GLOBAL CHINESA: INSERÇÃO COMERCIAL E PRODUTIVA COMPETITIVA}

As transformações verificadas na estrutura industrial chinesa, principalmente de seus setores metal-mecânico, eletroeletrônico e químico, evidenciam que foi a política industrial do país o fator determinante de sua estratégia de inserção internacional going global. Por meio de reorganização industrial (consolidação e eficiência), desenvolvimento tecnológico e capacidade de oferta em qualidade, quantidade e preço, combinada a uma política de atração de investimento, a China consolidou, no final da primeira década dos anos 2000, tecido industrial internacionalmente competitivo, capaz não apenas de atrair empresas estrangeiras para produzir em seu país, mas de articulá-las com as chinesas e, principalmente, dotá-las de capacidade de desenvolver tecnologias próprias na e a partir da China.

De acordo com a UNCTAD (2010), em 2009 a China representou o segundo maior destino de investimento. Se observado o montante mundial de IDE do tipo greenfield (destinados à abertura de novas fábricas industriais) em 2009, a China recebeu $8 \%$ do total investido no mundo, empatando em segundo lugar com o Reino Unido, tendo praticamente a mesma participação de toda a América Latina, que foi de $9 \%$. Quando analisado o destino desses investimentos dentro da economia doméstica chinesa, verifica-se que sua indústria manufatureira recebeu, em 2000 , o montante de US\$ 25,3 bilhões, registrando, em 2009, crescimento de $85 \%$. Este aumento no volume de ingressos permitiu à China atingir a cifra de US\$ 46,8 bilhões investidos nessa indústria, equivalente a $52 \%$ de todo investimento realizado nesse ano no país (CSY, 2010).

A competitividade adquirida pela sua indústria possibilitou a China tornar-se investidora internacional nos anos 2000 , por meio da internacionalização produtiva de suas empresas. O fato é corroborado pela saída de investimentos diretos do país em números consideráveis. Em 2009, por exemplo, o país atingiu a sexta posição dentre os maiores investidores do mundo, com fluxos de saída da ordem de US\$ 48 bilhões de dólares. Entretanto, se somado Hong Kong aos cálculos, esse montante sobe para US\$ 100 bilhões investidos em mercados estrangeiros, posicionando a China como a terceira maior investidora mundial em 2009 (UNCTAD, 2010).

Comercialmente, a China também sofreu consideráveis alterações ao longo 
dos anos 1990 e 2000. Essa modificação geral não foi somente devida exclusivamente a sua política industrial, por meio da reestruturação dos setores, mas da articulação desta com outras políticas, como a comercial, a cambial e a tecnológi$\mathrm{ca}$, que em seu conjunto permitiram extraordinário aumento do volume exportado, bem como a inserção internacional competitiva de sua indústria, realizada por meio da oferta de produtos com tendência de maior valor agregado e capazes de acessarem mercados diversificados e concorridos. Os anos 1990 se caracterizaram na China por uma reestruturação do padrão de comércio do país, pelo incremento tecnológico de suas exportações, principalmente no setor de máquinas e equipamentos (metal-mecânico) vis-à-vis uma redução gradual das exportações de baixo valor agregado, resultando em maior dinamismo econômico e industrial, que permitiu ao país ganhar mercados estrangeiros, deslocando tradicionais players globais.

A expansão comercial chinesa permitiu o país atingir o primeiro lugar no ranking de exportadores em 2009, ultrapassando a tradicional posição ocupada pela Alemanha. Este crescimento das exportações chinesas foi caracterizado por dois momentos específicos: os anos 1990 e a primeira década dos 2000 . Na primeira etapa, ocorreu o início do crescimento das exportações, atingindo uma média anual de $15,38 \%$. Na segunda etapa, que se iniciou nos anos 2000 , o incremento anual médio foi de $21,89 \%$ - ressalta-se que esse período inclui a crise de 2008 , que promoveu uma retração de aproximadamente $12 \%$ nas exportações mundiais. Durante as duas últimas décadas, as exportações chinesas tiveram um incremento de $1.853 \%$, enquanto o Brasil cresceu $387 \%$ e a Alemanha, tradicional potência exportadora, apenas $167 \%$ (WTO, 2011).

Estes resultados foram puxados, em grande parte, pelo desempenho exportador dos setores priorizados pela política industrial chinesa. Com relação ao setor metal-mecânico, a China, incentivada pela sua política industrial, ampliou seu espaço como fornecedora mundial, registrando, para o período 2005-2009, expressiva evolução em sua participação no total mundial exportado do setor metal-mecânico. Nesse período, os chineses conquistaram crescimento de $61,27 \%$ em sua contribuição nas exportações mundiais do setor metal-mecânico, ao saltar de uma participação de $6,40 \%$, em 2005, para 10,32\%, em 2009. Na indústria química resultados similares ocorreram, com expansão muito acima da média mundial, permitindo aos chineses aumentarem sua participação de 2,8\%, em 2005, para $6,3 \%$, em 2009. Já em eletroeletrônicos, no mesmo período, a expansão cresceu 5,4 pontos percentuais, passando a responder, em 2009 , por $21,8 \%$ das exportações mundiais de eletroeletrônicos (WTO, 2011).

\section{CONSIDERAÇÕES FINAIS}

A China despontou, rapidamente, como a segunda economia mundial, iniciando intenso processo de inserção internacional, que vem acirrando a concorrência global, deslocando tradicionais players dos mais diversos mercados e definindo nova geografia econômica mundial. Muitos estudos e pesquisas estão sendo desen- 
volvidos com vistas a entender e qualificar o fenômeno chinês, desvendando as suas estratégias. O presente artigo buscou caracterizar o desempenho econômico chinês, focando, sobretudo, as determinantes que possibilitaram ao país se inserir internacionalmente com rapidez e competitividade.

Entre 1990 e 2009 a China experimentou um rápido processo de industrialização, aumentando a capacidade de oferta de setores estratégicos (dinamizadores) de competitividade, o que possibilitou sua expressiva inserção comercial e produtiva nos mercados estrangeiros, materializando sua estratégia going global. Desde 1990, o país vem experimentando mudanças significativas em seu tecido industrial, consolidando setores prioritários (metal-mecânico, químico e eletroeletrônico) em grandes grupos corporativos, os quais possuem metas e passam a contar com amplo apoio governamental em suas estratégias de produção e inovação.

A partir de 2002, a China passou a fornecer "uma série de incentivos para promover a internacionalização das suas empresas, desde mecanismos de financiamento até a facilitação do processo administrativo para a realização de investimentos diretos no exterior" (Acioly \& Leão, 2011, p. 53). Contudo, embora grande parte do crescimento e inserção internacional chinês possa ser atualmente creditada a sua política de depreciação cambial e a sua política comercial de incentivos à exportação e investimentos no exterior, as análises realizadas neste artigo indicam que a determinante central do crescimento chinês foi sua política industrial. A preexistência da política industrial configurou uma indústria competitiva mundialmente e, somente após sua consolidação, as políticas cambiais e de incentivos foram utilizadas para potencializar o processo em curso.

A formulação e implementação de uma política industrial ao longo dos últimos quatro Planos Quinquenais pavimentaram as bases industriais e microeconômicas da China, possibilitando a consolidação de uma estratégia nacional de desenvolvimento going global, realizada por meio de uma ação concertada entre agentes, via planejamento institucional articulado em várias frentes e com horizonte de longo prazo. Tal estratégia, delineada a partir de questões estruturais e conjunturais tanto internas quanto externas, vem direcionando e articulando a economia chinesa, implementando reformas contrárias àquelas preconizadas pelas instituições multilaterais e mainstream econômico, de cunho intensamente liberal. Os chineses, nesse ponto, alinham-se com a ideia de que no contexto da economia global a participação do Estado é imprescindível.

Com isso, pode-se dizer que a China está, a exemplo do pragmatismo com planejamento econômico, comum dos japoneses e sul-coreanos (Masiero, 2003), vivenciando nova "era de rápido crescimento econômico" (Kosai, 1984), tal qual o Japão no imediato pós-guerra ou a coreana entre os anos 1970 e 1990. Contudo, ao que tudo indica, a evolução chinesa, de maior intensidade e duração do que as experiências de seus vizinhos asiáticos, parece não ter tomado conhecimento das prescrições usuais, seguindo com a orquestração de políticas cambiais, de investimento e tecnológicas, alinhadas a partir de uma política industrial. A tendência continua e é soberana, já relevando resultados que permitem constatar uma nova configuração e ciclo de desenvolvimento industrial do país, agora mais empresarial. 
Afinal, a expansão industrial e internacional da China como resultado da articulação de políticas setoriais, também permitiu modificações em processos internos de suas empresas, destacadamente de gestão, tecnologia e produtos. Essa trajetória empresarial pode ser concebida, conforme Matthews (2006), pela capacidade que a indústria chinesa de setores prioritários teve de promover e realizar diversificadas combinações de linkages, leverage e learning por meio do suporte de seu Estado. Isto é, a partir do momento em que o Conselho de Estado decidiu industrializar o país em setores estratégicos de valor agregado, verificou-se que esse processo seria mais intenso, e benéfico ao país, se a atratividade das tecnologias necessárias via importação e investimentos estrangeiros não fossem motivadas apenas pelos fatores de produção e legislação do país, mas, principalmente, se articulando com as empresas chinesas. Observou-se na China um modelo conduzido e articulado pelo Estado em que as empresas nacionais passaram a receber tecnologia (linkage), as quais foram implementadas e desenvolvidas em parceria (leverage), propiciando aprendizado rápido (learning), capacitando-as a gerar inovações locais (indigenous innovation).

As empresas chinesas contemporâneas, nestes termos, passam a promover grande ruptura de trajetória, rapidamente se tornando contribuintes de valor adicionado, extrapolando as suas vantagens comparativas locacionais em mão de obra para se dotarem de vantagens competitivas, sendo uma de suas principais a capacidade de inovar em custo (Zeng \& Williamson, 2007). Atualmente, a indústria chinesa contribui em vários processos de manufatura com destacado know-how em inovar maneiras de se entregar altas tecnologias com baixo custo. Os chineses do século XXI aprenderam a manufaturar e contribuem para realizar esse processo a custos mais baixos, não por meio de salários baixos necessariamente, mas em inovações em processos e produtos (Zeng \& Williamson, 2007) - vantagem e diferencial atingidos tanto pelo processo qualificado de políticas públicas articuladas quanto pelas próprias características de seu mercado interno (altamente demandante com baixo poder aquisitivo). Nesse sentido, a percepção de produtos "made in China" a "preços chineses", isto é, de baixa qualidade, muito baratos, fabricados por estrangeiros ou por empresas chinesas pouco experientes em manufatura, aos poucos migra para a constatação de produtos desenvolvidos e criados na China, com valores adicionados no país, por meio de inovações em processos e tecnologia, não apenas por multinacionais de fora, mas também por um crescente número de empresas genuinamente chinesas. Com isso, a China não se torna apenas o workshop of the world (Gao, 2011), mas um player competitivo em tecnologia, inovação e valor agregado. Inclusive, essa tendência já pode ser verificada em casos de setores de alta tecnologia, tais como: a expansão da Haier no mercado mundial de eletrodomésticos; a Galanz com mais da metade do mercado global de micro-ondas; a ChinaMedical como líder mundial no desenvolvimento de ultrassom; a BYD como segunda maior fabricante do mundo de baterias recarregáveis; a Vimicro com mais de $60 \%$ do mercado internacional de processadores multimídia; entre outros (Zeng \& Williamson, 2007).

Com esses processos e resultados analisados, a China descortina questões re- 
flexivas aos demais países. No Brasil, por exemplo, em contraste à China, não se tem conseguido estabelecer uma estratégia nacional, capaz de articular planejamentos, projetos e políticas de desenvolvimento no longo prazo. Pode-se argumentar que o Plano de Metas e os Planos Nacionais de Desenvolvimento (PND) foram os que mais se aproximaram dessa ideia quanto à sua forma. Todavia, em períodos recentes, pós-anos 1990, o que se vislumbrou foram políticas isoladas, não totalmente articuladas, que tentaram resolver problemas específicos, principalmente os fiscais, cambiais ou inflacionários, mas nunca de forma articulada com os agentes produtivos e com fraca capacidade de mobilização e liderança do Estado. Privilegiam-se os sintomas, não as causas. Em relação à indústria, a situação é mais proeminente, com dificuldades contemporâneas de se desenhar uma política eficaz, apesar de alguns esforços, como a Política Tecnológica, Industrial e de Comércio Exterior - PITCE. Não por acaso, como destacaram Suzigan e Furtado (2006, p. 163), "um dos aspectos mais marcantes do atraso no desenvolvimento econômico - e por extensão no desenvolvimento social - do Brasil tem sido o fraco desempenho da indústria de transformação".

As análises realizadas indicam que a determinante do processo de crescente importância internacional da indústria de transformação chinesa se encontra na maneira e padrão da industrialização do país, conduzida por meio e majoritariamente a partir de sua política industrial, que atingiu êxito expressivo em aproximadamente quinze anos: em um primeiro momento, constituiu uma indústria que abastecesse sua indústria doméstica com competitividade (produtividade e qualidade), e, em um segundo momento, agregou maior valor às exportações, reestruturando sua pauta com maior presença dos setores manufatureiros, principalmente aqueles de tecnologia metal-mecânica, eletroeletrônica e química, para, atualmente, conquistar importantes posições setoriais internacionalmente.

A conclusão mais plausível de todo este processo é que ao mesmo tempo em que o Estado chinês desestatizou a sua economia, tornou-se mais proativo na articulação e coordenação dos agentes produtivos (nacionais e internacionais), orientando-se pela estratégia going global, conduzida pragmaticamente por diretrizes estabelecidas em seus Planos Quinquenais. Com Estado ativo, mas não estatizante, a China tornou-se referência incontornável, tanto pelas ameaças quanto pelas oportunidades que gera, forçando os demais países a cada vez mais desenvolver suas estratégias e trajetórias com os chineses e apesar dos chineses, mas não sem os chineses.

\section{REFERÊNCIAS BIBLIOGRÁFICAS}

ACEMOGLU, D. (2009) Introduction to modern economic growth. Oxford: Princeton University Press.

ACIOLY, L.; LEÃO, R. P. (2011) China. In: Internacionalização de empresas: experiências internacionais selecionadas. ACIOLY, L.; LIMA, L. A. F.; RIBEIRO, E. (Orgs). Brasília: IPEA.

AIGINGER, K. (2007) Industrial policy: a dying breed or a re-emerging phoenix. Journal of Industrial, Competition and Trade, v.7, pp.297-323. 
AMSDEN, A. H. (2009) A ascensão do "resto": os desafios ao Ocidente de economias com industrialização tardia. São Paulo: Editora UNESP.

BAILEY, D.; LENIHAN, H; SINGH, A. (2009) Lessons for African economies from Irish and East Asian industrial policy. Journal of Industrial, Competition and Trade, v.9, pp.357-382.

BOULTON, W. R. (1997) Hong Kong - South China electronics industry. In: KELLY, M. B., W. (Ed.). Electronics manufacturing in the Pacific Rim. Maryland: International Technology Research Institute.

BRESSER-PEREIRA, L. C. (2006) Estratégia nacional e desenvolvimento. Revista de Economia Política, v.26, n.2, pp.203-230.

BUIRA, A. (2004) The dogmatism of Washington Consensus. In: TEUNISSEN, J. J; AKKERMAN, A. (Eds). Diversity in development: reconsidering the Washington Consensus. The Hague: FONDAD. Disponível em: http://www.fondad.org/uploaded/Diversity\%20in\%20Development/Fondad-Diversity-Contents-Contributors.pdf. Acesso em 8 de dezembro de 2011.

CASTELLS, M. (1999) A sociedade em rede. Rio de Janeiro: Paz e Terra.

CHANDLER, Jr. A. (1994) Scale and scope: the dynamics of industrial capitalism. Cambridge: Harvard University Press.

CHENERY, H. B.; ROBINSON, S.; SYRQUIN, M. (1986) Industrialization and growth: a comparative study. Washignton: World Bank.

CHINA CHEMICAL REPORTER (1996) Disponível em: http://www.ccr.com.cn/new/. Acesso em 8 de dezembro de 2011.

CSY - China Statistical Yearbook (2011) National statistical database. Disponível em: http://www. stats.gov.cn.. Acesso em 8 de dezembro de 2011.

DICKEN, P. (2010) Mudança global: mapeando as novas fronteiras da economia mundial. Porto Alegre: Bookman.

FAJNZYLBER, R. F. (1983) La Industrializacion trunca de América Latina. México: Nueva Imagem,.

GAO, Y. (2011) China as the workshop of the world: an analysis at the national and industrial level of China in the international division of labor. London: Routledge.

GILPIN, R. (2001) Global political economy. Princeton: Princeton University Press.

HEIDEN, P. T. (2011) Chinese sector industrial policy shaping international trade and investment patterns - evidence from the iron and steel industry. Institute of East Asian Studies. Duisburg working paper on East Asian Studies. N. 88.

KALDOR, N. (1970) The case for regional policies. Scottish Journal of Political Economy, November.

KOSAI, Y. (1984) The era of high speed growth: notes on the modern Japanese economy. Tokyo: University of Tokyo.

KRÜGER, J. (2008) Productivity and structural change: a review of literature. Journal of Economic Surveys, v.22, n.2, pp.330-363.

LALL, S. (2000) Selective industrial and trade policies in developing countries: theoretical and empirical issues. QEH Working Paper Series, n.48.

LALL, S. (2004) Reiventing industrial strategy: the role of Government policy in building industrial competitiveness. Discussion Paper $N^{\circ} 28$, InterGovernmental Group of Twenty-four, United Nations.

LIN, C. (2001) Industry policies and structural change in China, 1979-2000. National Policy Foundation. NPF Research Report, June 8.

MARRONE, P. (2006) China e seus efeitos sobre a indústria de máquinas equipamentos do Brasil. São Paulo: Magma Cultural.

MASIERO, Gilmar (2003) Pragmatism and planning in East Asia and Brazil. In: SMITH, P. H., HORISAKA, K.; NISHIJIMA, S. East Asia and Latin America: the unlikely alliance. New York: Rowman \& Littlefield Publishers, Inc.

MATHEWS, J. (2006) Dragon multinationals: New players in $21^{\text {st }}$ century globalization. Asia Pacific Journal of Management, n.23, pp.5-27.

NAUGHTON, B. (1996) Growing out of the plan: Chinese economic reform, 1978-1993. Cambridge: Cambridge University Press. 
NOLAN, P. (2001) China and the global economy: national champions, industrial policy, and the big business revolution. New York: Palgrave.

NOLAN, P. (2004) Transforming China: globalization, transition and development. London: Anthem Press,.

NOLAND, M.; PACK, H. (2005) The East Asian industrial policy experience: implications for the Middle East. Institute for International Economics Working Papers Series, WP05-14. Disponível em: http://www.iie.com/publications/wp/wp05-14.pdf. Acesso em 8 de dezembro de 2011.

OHMAE, L. (1990) The borderless world: power and strategy in the interlinked economy. New York: Free.

PACK, H.; SAGGI, K. (2006) The case for industrial policy: a critical survey. World Bank Policy Research Working Paper Series, n.3839. Disponível em: http://www-wds.worldbank.org/servlet/WDSContentServer/WDSP/IB/2006/01/31/000016406_20060131160754/Rendered/PDF/wps3839. pdf. Acesso em 8 de dezembro de 2011.

PORTER, M. (1989) A vantagem competitiva das nações. Rio de Janeiro: Elsevier.

RODRIGUEZ, F. (2007) Openness and growth: what have we learned? DESA Working Paper, n.51.

RODRIK, D. (2004) Industrial policy for the twenty-first century. Research paper - UNIDO. Disponível em: http://www.hks.harvard.edu/fs/drodrik/Research\%20papers/UNIDOSep.pdf. Acesso em 8 de dezembro de 2011.

RODRIK, D. (2008) Normalizing industrial policy. Working Paper $N^{\circ} 3$, Commission on Growth and Development, World Bank.

SOETE, L. (2007) From industrial to innovation policy. Journal of Industrial, Competition and Trade, v.7, pp.273-284.

STOPFORD, J. M. (1999) The growing interdependence between transnational corporations and Governments. In: BUCKLEY, P. J.; GHAURI, P. (Eds.). The global challenge for multinational enterprises: managing increasing interdependence. Oxford: Elsevier Science.

SUZIGAN, W.; FURTADO, J. (2006) Política industrial e desenvolvimento. Revista de Economia Política, v.26, n.2, pp.163-185.

UNCTAD - United Conference on Trade and Development (2011) Statistic database. Disponível em: http://unctadstat.unctad.org.. Acesso em 8 de dezembro de 2011.

WADE, R. (2010) After the crisis: industrial policy and development state in low-income countries. Global Policy, v.1, n.2, pp.150-161.

WORLD BANK (2011) Online statistical database. Disponível em http://data.worldbank.org/. Acesso em 8 de dezembro de 2011.

WTO - World Trade Organization (2011) Statistic database. Disponível em: http://stat.wto.org. 2011. Acesso em 8 de dezembro de 2011.

VIETOR, R. H. (2007) How countries compete: strategy, structure, and Government in the global economy. Boston: HBS Press.

ZENG, M.; WILLIAMSON, P. (2007) Dragons at Your Door: How Chinese Cost Innovation Is Disrupting Global Competition. Harvard Business School Press.

ZWEIG, D. (2002) Internationalizing China: domestic interests and global linkages. Ithaca and London: Cornell University Press. 